\title{
Drowsiness Detection Methods for Driver's: A Review
}

\author{
Vrushali B.Ghule \\ M.E. Student \\ Department of Electronics, \\ AVCOE, Sangamner
}

\author{
S.S.Katariya \\ Assistant Professor \\ Department of Electronics, \\ AVCOE, Sangamner
}

\begin{abstract}
After doing survey we come to the point that more accidents are happen due to the driver drowsiness. So now a day's driver drowsiness is the major cause face by the people. We are discussing here the various driver drowsiness detection techniques using their features. We specially give the focus on the computer vision based technique.
\end{abstract}

\section{General Terms}

Driver Drowsiness, Saftey, Image Processing.

\section{Keywords}

Drowsiness detection, Eye Blinking frequency, Eye detection.

\section{INTRODUCTION}

While designing the car, comfort zone and safety are the main factors. But due to Driver drowsiness the safety point will not be fulfilled. Drowsiness can be happened due to various reasons which shows by following fig.

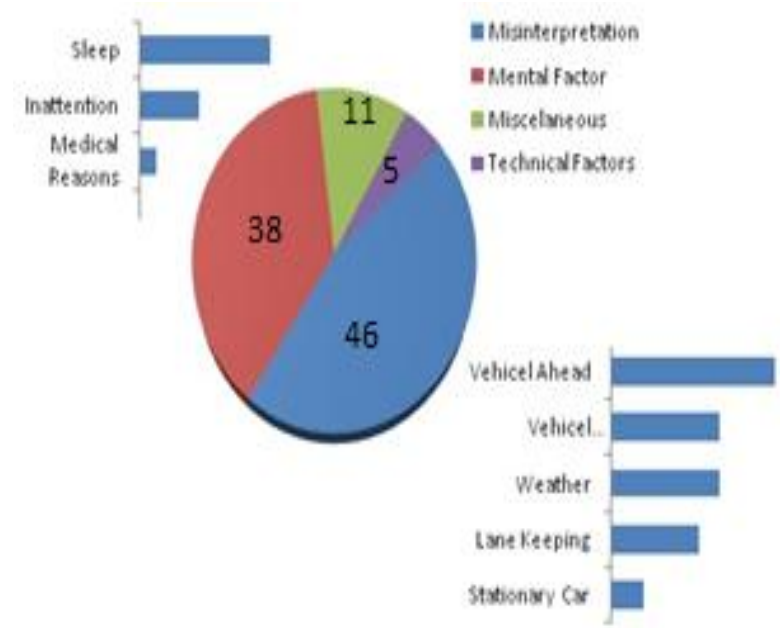

Fig 1: Reasons for Drowsiness

To avoid accidents due to drowsiness there are many different techniques are available.

\section{DIFFERENT DROWSINESS DETECTION TECHNIQUES}

As shown in following Fig.2, there are main three techniques are used. They are as:
A) Based on Image Processing
B) Based on EEG

C) Based on Artificial neuron network

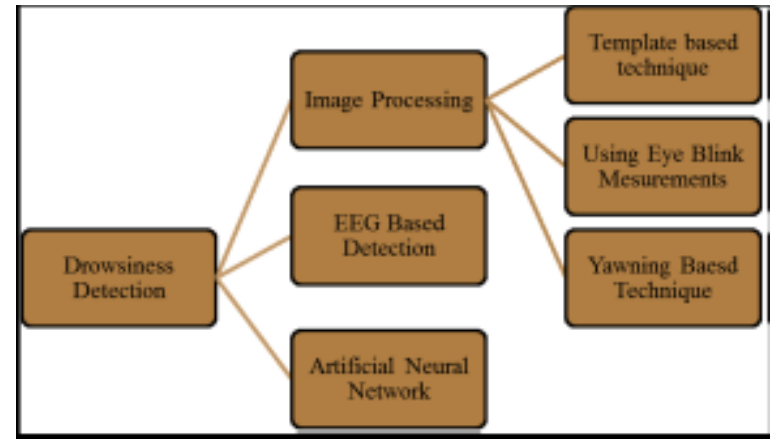

Fig 2: Different Drowsiness detection technique [1]

Detail explanation of above methods:

\subsection{Image Processing}

This method is further classified into three categories,

1) Template Matching Technique.

2) Using Eye Blink measurement.

3) Yawing based Technique.

\subsubsection{Template Matching Technique}

In this technique the template for the closed and open eyes are provided (see Fig 3). Then the state of driver's eyes is compared with this template, matches, then alarm are set or buzzer will on and we can prevent drowsy mode [12].
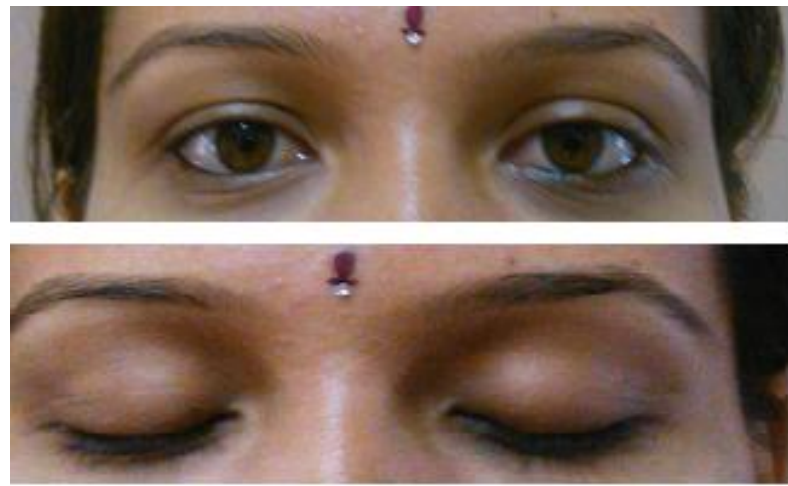

Fig. 3: Open and Closed Eye Template 


\subsubsection{Using Eye Blink Measurement}

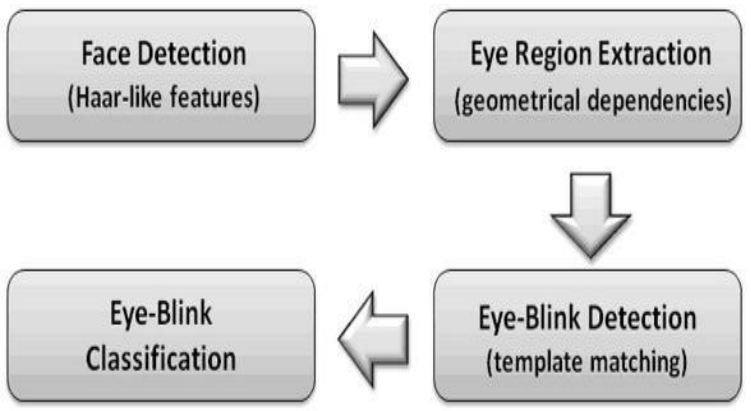

Fig 4: Algorithm for eye-blinking rate [11]

In this technique, eye blinking frequency and eye closer duration is calculated for detecting driver drowsiness. The eye blinking rate is compared with threshold value set by the programmer for the system [14].The following algorithm gives the detail working of the system.

\subsubsection{Algorithm:}

Step 1: Start

Step 2: Camera initialization and face detection

Step 3: Continuous monitoring of eyes

Step 4: Counting the blinking frequency of eyes.

Step 5: Compared with threshold value.

Step 6: Check the mode.

Step 7: Awake mode else if drowsy mode else very drowsiness.

Step 8: Awake mode

Step 9: No Alarm

Step 10: Drowsy mode or very drowsy mode

Step 11: Alarm on

Step 12: Stop.

\subsubsection{Based on yawing:}

In this technique the normal mouth image is compared with yawn mouth image. First take image of the face by camera placed in front of the driver seat in the car. Then it detects the mouth position of face and continuously monitored it [13] when the rate of yawn is higher than normal condition then it indicates the drowsiness state.

\subsection{Technique based on EEG}

There are different physiological signals are available to detect drowsiness ,such as EEG,ECG,Heart Rate(HR).In EEG technique the helmet is used which includes various wiring and all. The heart rate can be measured by ECG.Following fig. shows the physiological signal sensing system [15].

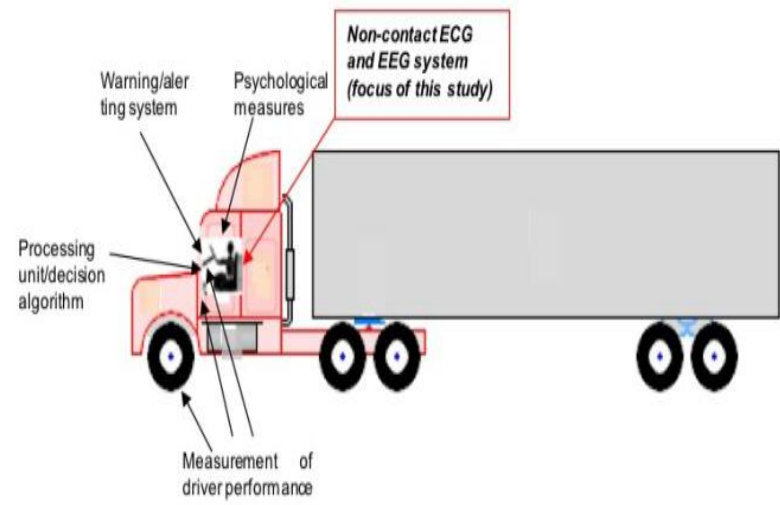

Fig 5: Schematic of sensing system integration for driver drowsiness detection and assistance [10]

\subsection{Based on Artificial neural network:}

In this technique neurons are used. But from accuracy point of view calculating using only one neuron is not sufficient. So more than one neuron are used by many researcher [16].Following Fig.6 shows working of ANN:

\section{Capture Image}

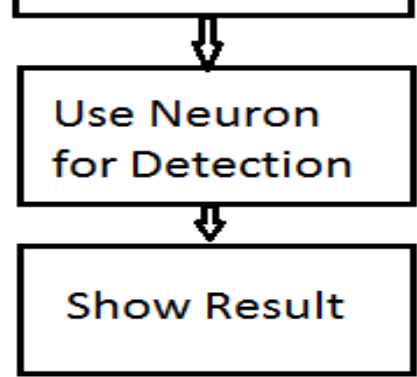

Fig 6: Working of ANN [1]

\section{SUMMARY DROWSINESS DETECTION TECHNIQUES}

Table 1: Different Drowsiness Detection Techniques

\begin{tabular}{|l|l|l|}
\hline $\begin{array}{l}\text { Name of } \\
\text { Techniques }\end{array}$ & $\begin{array}{l}\text { Feature Used by } \\
\text { technique }\end{array}$ & Efficiency \\
\hline $\begin{array}{l}\text { Template Matching } \\
\text { Technique }\end{array}$ & $\begin{array}{l}\text { Saved Database } \\
\text { of closed and } \\
\text { open eyes are } \\
\text { used as template }\end{array}$ & $\begin{array}{l}\text { Depend on the } \\
\text { required results } \\
\text { this method is } \\
\text { used and it is } \\
\text { efficient. }\end{array}$ \\
\hline $\begin{array}{l}\text { Using Eye Blink } \\
\text { Measurement }\end{array}$ & $\begin{array}{l}\text { Eye blink } \\
\text { frequency count } \\
\text { is used }\end{array}$ & $\begin{array}{l}\text { Efficient as } \\
\text { calculations of eye } \\
\text { blinking is easy } \\
\text { and also gives } \\
\text { very good result }\end{array}$ \\
\hline Based on yawing & $\begin{array}{l}\text { Frequency of } \\
\text { yawing is used }\end{array}$ & Not used often. \\
\hline Technique Based & Electrode helmet & $\begin{array}{l}\text { As electrode } \\
\text { helmet is difficult }\end{array}$ \\
\hline
\end{tabular}




\begin{tabular}{|l|l|l|}
\hline on EEG & is wear & $\begin{array}{l}\text { to wear all the } \\
\text { time while driving } \\
\text { so this system is } \\
\text { not very efficient. }\end{array}$ \\
\hline $\begin{array}{l}\text { Based on Artificial } \\
\text { Neural Network }\end{array}$ & $\begin{array}{l}\text { More than one } \\
\text { neuron is used }\end{array}$ & $\begin{array}{l}\text { Many neurons has } \\
\text { to used for proper } \\
\text { calculation so not } \\
\text { used much. }\end{array}$ \\
Not very efficient
\end{tabular}

\section{RELATED WORK}

Ralph Oyini Mbouna et al.[3] gives the detail analysis of the head position and the eye state of the driver are monitor. In this SVM (support vector machine) classifies the series of video frames into awake or drowsy driving events. From experimental results it shows that their system has high classification recovery with low errors and that results in the prevention of false alarm. Anirban dasgupta et al.[4] proposed the robust real time embedded platform which is used to detect the drowsiness of the driver during day night. They used haar like features to face detection. On day time principal component analysis is used for eyes detection while local binary pattern features used for night time. This system is better related to speed and accuracy. Antoine Picot et al.[5] they focus on brain and visual activity of driver for drowsiness detection. Electroencephalogram (EEG) is used to check the brain activity while eye blinking detection is used for visual activity, which is obtained by an electrooculogram (EOG). From the result it proves that EEG and EOG detectors are good because signal from EEG are checked with signals of EOG, because of this fake alarm rate decreases up to $5 \%$ Boon-Giin Lee et al.[6] states the drowsiness of the driver is detected by the eye movement monitoring and bio signal processing. An android based smart phone is used for collect the data and for further processing. To sensors are used by Boon-Giin Lee' and Wan - Young-Chung for driver image video sensor and for driver photoplethysmogrph signal, biosignal sensor is used.

\section{CONCLUSION}

After discussing the different techniques used for detection of drowsiness, we came to know that according to the condition different techniques are used. Artificial Neural network technique is not very efficient as many neurons have to use for proper results. EEG based technique is also not efficient as driver has to wear electrode helmet. So now a day much attention is given on the image processing based techniques and that also gives proper results. More study is needed in Eye Blinking Frequency Count technique, comes under image processing, which can be cheapest and correct method to detecting the drowsiness of driver.

\section{REFERENCES}

[1] Jay Fuletra, Dulari Bosamiya," A Survey on Driver's Drowsiness Detection Techniques", International Journal on Recent and Innovation Trends in Computing and Communication vol-1 issue-11,816-819

[2] Vandana Saini, Rekha Saini," Driver Drowsiness Detection system and techniques".
[3] Ralph Oyini Mbouna, Seong G. Kong, Senior Member, IEEE,(2013),Visual Analysis of Eye State and Head Pose for Driver Alertnes Monitoring, (IEEE),pp.14621469,vol.14,USA

[4] Anirban dasgupta,anjith george,"A Vision Based System For Monitoring The Loss Of Attention in Automotive Drivers",(IEEE Transaction),vol.14,no.4 2013

[5] AntoinePicot,SylvieCharbonnier,"On-Line Detection of Drowsiness Using Brain and Visual Information",IEEE Transaction on systems, man and cybernetics part a: systems and humans, VOL. 42, NO.3,2012

[6] Boon-Giin Lee and Wan-Young Chung, "Driver Alertness Monitoring Using Fusion of Facial Features and Bio-Signals", (IEEE) Sensors journal, vol. 12, no. 7,2012 .

[7] Ralph Oyini Mbouna, Seong G. Kong, Senior Member, "Visual Analysis of Eye State and Head Pose for Driver AlertnessMonitoring",IEEE transactions on intelligent transportation systems, VOL. 14, NO. 32013

[8] Rami N. Khushaba, Sarath Kodagoda, Sara Lal, and Gamini Dissanayake,'Driver Drowsiness Classification Using Fuzzy Wavelet-Packet-Based Feature-Extraction Algorithm", (IEEE) Transactions vol. 58, no. 1, 2011.

[9] Wei Zhang, Bo Cheng, Yingzi Lin,” Driver Drowsiness Recognition Based on Computer Vision

[10] Technology",(IEEE) Vol.17, No.3, 2012. 2, No.6,2012Technologies l'2012 IEEE.

[11] Dr. Xiong (Bill) Yu, P.E.,"Non-Contact Driver Drowsiness Detection System",(safety IDEA),2012

[12] Aleksandra Krolak, Pawel Strumillo, "Eye-Blink Detection System for Human-Computer Interaction" http://www.medialt.no/pub/uikt/u2010/011Krolak/index.html

[13] D.Jayanthi, M.Bommy," Vision-based Real-time Driver Fatigue Detection System for Efficient Vehicle Control", International Journal of Engineering and Advanced Technology (IJEAT) ISSN: 2249 - 8958, Volume-2, Issue-1, October 2012

[14] Behnoosh Hariri, Shabnam Abtahi , Shervin Shirmohammadi, Luc Martel," A Yawning Measurement Method to Detect Driver Drowsiness" Distributed and Collaborative Virtual Environments Research Laboratory, University of Ottawa, Ottawa, Canada .

[15] Artem A. Lenskiy and Jong-Soo Lee, "Driver's Eye Blinking Detection Using Novel Color and Texture Segmentation Algorithms", International Journal of Control, Automation, and Systems,pp.317-327, 2012.

[16] Karamjeet Singh,Rupinder Kaur,"Physical and Physiological Drowsiness Detection Methods", IJIEASR, pp.35-43,vol.2,2013.

[17] Er. Manoram Vats and Er. Anil Garg," Detection And Security System For Drowsy Driver By Using Artificial Neural Network Technique", International Journal of Applied Science and Advance Technology January-June 2012, Vol. 1, No. 1, pp. 39-43 